Revista Energia na Agricultura

ISSN 1808-8759

\title{
DETERMINAÇÃO DAS COORDENADAS DOS VÉRTICES LIMÍTROFES DE IMÓVEIS RU- RAIS UTILIZANDO-SE DO POSICIONAMENTO GPS ${ }^{1}$
}

MAURO ISSAMU ISHIKAWA² \& ZACARIAS XAVIER DE BARROS ${ }^{3}$

RESUMO: Visando avaliar metodologias de levantamentos incluídos na Norma Técnica para Georreferenciamento de Imóveis Rurais, estabelecidos pelo INCRA, em atendimento a Lei n. 10.267/01, e considerando aspectos de precisão e acurácia, uma área teste foi implantada no Assentamento Florestan Fernandes, no município de Presidente Bernardes, SP. Essa área foi subdividida em três subáreas de modo a simular a existência de três imóveis contíguos. A primeira etapa do trabalho consistiu na implantação e determinação das coordenadas dos vértices de apoio básico nas respectivas áreas. Esses vértices foram determinados a partir do processo de transporte direto, utilizando-se receptores de dupla frequência (L1/L2) e através do processo de poligonal com linhas de base não superior a $20 \mathrm{~km}$, com receptores de simples freqüência (L1). As coordenadas dos vértices limítrofes das três subáreas foram determinadas utilizandose GPS de simples freqüência, a partir de dois processos de levantamento, ambos utilizando o método de posicionamento relativo estático. O primeiro, denominado de poligonação, teve cada vértice que delimita a propriedade ocupada sucessivamente, partindo-se de um ponto de apoio básico e fechando em outro. No segundo, com duplas linhas de base, ou seja, dupla irradiação, cada vértice limítrofe da propriedade foi irradiado a partir de dois vértices do apoio básico. Esses procedimentos foram realizados com o intuito de se definir e implementar uma estratégia de controle de erros, realizar medidas redundantes e empregar um método de ajustamento adequado, para que seja possível obter valores confiáveis dentro dos padrões exigidos em cada tipo de levantamento. Com os dados coletados e processados, algumas análises foram realizadas a partir das discrepâncias entre as coordenadas obtidas por diferentes metodologias GPS. Os resultados foram considerados satisfatórios e atenderam às prescrições da Norma Técnica.

Palavras-chave: Lei n. 10267/2001, georreferenciamento de imóveis rurais, GPS.

\footnotetext{
${ }^{1}$ Parte do trabalho de Tese

2 2Aluno de doutorado do Programa de Pós-Graduação em Agronomia (Energia na Agricultura), Faculdade de Ciências e Tecnologia - FCT/UNESP - Departamento de Cartografia, Rua Roberto Simonsem, 305 - 19060-900 - Presidente Prudente - SP, mauro@,fct.unesp.br

3 3Orientador e Docente, Faculdade de Ciências Agronômicas - FCA/UNESP - Departamento de Engenharia Rural, Fazenda Experimental Lageado - 18610-307 - Botucatu - SP, zacariasxb@fca.unesp.br
} 


\section{DETERMINATION OF THE COORDINATES OF POINTS LIMITS OF RURAL PARCELS USING POSITIONING GPS}

SUMMARY: Aiming to evaluate the methodologies of surveys related with the specifications of Georeferencing Rural Parcels in Brazil, established by INCRA (National Institute of Colonization and Agrarian Reform), in attendance to the Law 10.267/01, and considering aspects of precision and accuracy, a test area was set up in the Assentamento Florestan Fernandes, in the county of Presidente Bernardes, SP. This area was subdivided in three sub-areas in order to simulate the existence of three contiguous rural parcels. The first stage of work consisted in the implantation and determination of the control points coordinates in their respective areas. These control points were determined by the process of direct transport, using dual frequency (L1/L2) GPS receivers and through the process of traverse with baselines of up to $20 \mathrm{~km}$, using single frequency receivers (L1). The coordinates of the points of the perimeter of the three sub-areas were determined using single frequency GPS receivers, from two survey methods, both using static relative positioning. The first one, so called traverse, each point that delimits the property was occupied successively, starting from the control point and closing at another. In other, denominated double irradiation, each point of the property was irradiated from two control points. These procedures were accomplished with the intention to define and to implement a mistake control strategy, to realize redundancy measurements and to use an adjustment method correctly, to obtain trustworthily values in the patterns demanded in each kind of survey. With the data collected and processed some analyses could be accomplished from the discrepancies between the coordinates obtained by different methodologies. The results show that this test area may be used to validate other methodologies and equipments. The results were satisfactory and attended the specifications of Geo-referencing Rural Parcel.

Keywords: Law 10267/2001, geo-referencing rural parcels, GPS.

\section{INTRODUÇÃO}

Os levantamentos geodésicos e topográficos, de uma forma geral, baseiam-se em medições de várias naturezas com o objetivo de determinação de ângulos, distâncias e posições. É importante entender que toda medição realizada pelo homem pode conter erros, não importando a tecnologia utilizada, os quais 
se propagam quando realizam estes levantamentos, afetando, por exemplo, a determinação de coordenadas dos vértices limítrofes de uma propriedade.

Os problemas tratados pela geodésia, tal como em algumas outras ciências, envolvem a estimação de incógnitas, que são obtidas a partir de dados experimentais. A cada observação coletada corresponde uma expressão, linear ou não, envolvendo os parâmetros de interesse. Como exemplo de um problema geodésico pode-se citar a determinação de coordenadas das estações de uma poligonal que delimita uma propriedade. Neste caso, as observações são coletadas, com uma estação total e/ou receptores GPS, dentre outras possibilidades. No ajustamento, essas observações são expressas em função das coordenadas das estações (parâmetros). Os dados coletados podem estar contaminados por erros sistemáticos e grosseiros, além dos inevitáveis erros aleatórios. Esses últimos constituem uma característica das observações, as quais podem ser coletadas em número maior ou menor que o mínimo necessário para solução única do problema. Enquanto o primeiro caso conduz a um modelo matemático com dados redundantes, o segundo proporciona um modelo indeterminado (MONICO; SILVA, 2003).

Ao estabelecer a relação entre observações e parâmetros, o geodesista está definindo o modelo matemático funcional. A redundância de dados possibilita a aplicação de controle de qualidade aos resultados do experimento. Na prática, o controle de qualidade já se inicia na fase do planejamento, o qual, em se tratando de um levantamento geodésico, envolve três fatores: economia, precisão e confiabilidade (TEUNISSEN, 2000). Dentro deste contexto, um experimento ideal deve apresentar confiabilidade e precisão máxima a um custo mínimo. Economia expressa os custos das observações, transporte, monumentação etc. Precisão, que é dada pela matriz variância-covariância dos parâmetros (coordenadas), representa a característica do levantamento em propagar erros aleatórios. Admite-se neste caso, a inexistência de erros sistemáticos. A confiabilidade está relacionada com a capacidade das observações redundantes em detectar erros no modelo e no próprio levantamento (MONICO; SILVA, 2003).

Desta forma, no planejamento dos levantamentos, os aspectos relacionados com confiabilidade são de extrema importância, muito embora às vezes sejam negligenciados. A coleta de dados deve ser realizada com todo o cuidado e de acordo com o planejado. Mas, mesmo assim, vários fatores externos afetam a qualidade das observações. Por fim, a precisão obtida no processo de ajustamento deve ser avaliada com rigor.

A Portaria $\mathrm{n}^{\circ}$ 954, de 13 de novembro de 2002 (BRASIL, 2002b), estabeleceu em seu artigo primeiro que "o indicador da precisão posicional a ser atingido na determinação de cada par de coordenadas, relativas a cada vértice definidor do limite do imóvel, não deverá ultrapassar o valor de 0,500 m”. 
Portanto, é necessário definir e implementar uma estratégia para alcançar essa precisão e realizar medidas redundantes empregando um método de ajustamento adequado para que seja possível obter valores confiáveis dentro dos padrões exigidos em cada tipo de levantamento.

O Decreto $\mathrm{n}^{\circ}$ 4.449, de 30 de outubro de 2002 (BRASIL, 2002a), que regulamentou a Lei em questão, atribuiu ao INCRA a competência de certificar que a poligonal objeto do memorial descritivo não se sobreponha a outro imóvel que conste de seu cadastro georreferenciado, bem como atenda à precisão estabelecida pelo Ato Normativo.

As coordenadas dos vértices, certificadas pelo INCRA, mediante análise, amostragem e aprovação das determinações a ele submetidas, tem o efeito de produzir direitos legais, quando do registro do imóvel georreferenciado. Constituem, portanto, pontos de referência para os novos levantamentos a serem realizados. Vértices comuns a dois ou mais imóveis, cujas coordenadas já tenham sido certificadas pelo INCRA permitirão que se possa obter não apenas a precisão atingida nas observações, mas também a acurácia cometida na sua determinação (INSTITUTO NACIONAL DE COLONIZAÇÃO E REFORMA AGRÁRIA, 2003).

Nesse contexto, este trabalho tem por objetivo identificar procedimentos e metodologias de levantamentos para o georreferenciamento de imóveis rurais utilizando-se do posicionamento GPS, de modo a atender aos dispositivos da Lei $\mathrm{n}^{\circ}$. 10.267/2001 (BRASIL, 2001), considerando aspectos de precisão e acurácia, de modo a fornecer, aos profissionais que atuam nesta área, elementos apropriados para avaliar e certificar os levantamentos.

\section{MATERIAL E MÉTODOS}

O Assentamento Florestan Fernandes, administrado pelo Instituto de Terras do Estado de São Paulo - ITESP, está localizado no quarto perímetro de Presidente Prudente - Município de Presidente Bernardes, entre as latitudes $22^{\circ} 17^{\prime} \mathrm{S}$ e $22^{\circ} 19^{\prime} \mathrm{S}$ e as longitudes $51^{\circ} 40^{\prime} \mathrm{W}$ e $51^{\circ} 42^{\prime} \mathrm{W}$, distante aproximadamente $48 \mathrm{~km}$ de Presidente Prudente, e possui uma área de 1.115 hectares.

Com o objetivo de simular a existência de imóveis vizinhos, e desta forma permitir realizar uma avaliação do georreferenciamento a partir de análises nas discrepâncias das coordenadas entre os vértices comuns, implantaram-se três áreas, sendo estas denominadas de Área 1, Área 2 e Área 3, com 5, 6 e 5 vértices, respectivamente. A Figura 1 apresenta a divisão da área de estudo, sendo os vértices limítrofes indicados pela letra $\mathrm{M}$ e os vértices de apoio básico pela letra $\mathrm{A}$. 


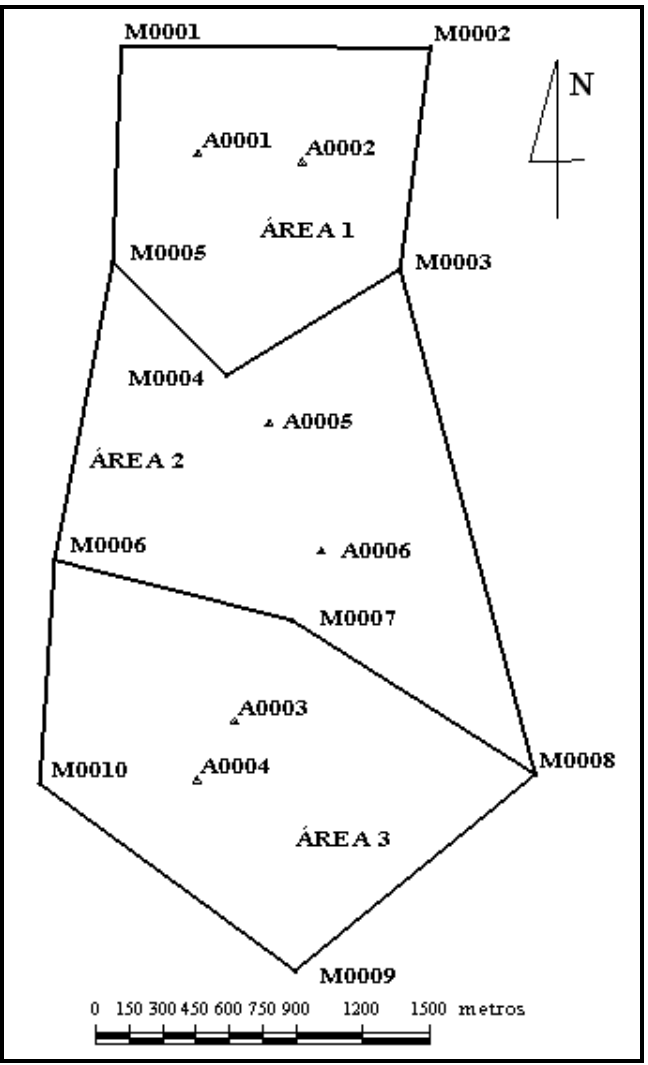

Figura 1 - Divisão da área de estudo.

\subsection{Determinação das coordenadas dos vértices de apoio básico}

As coordenadas dos vértices de apoio básico devem ser determinadas com o intuito de serem utilizadas como estações base, de coordenadas conhecidas, no cálculo das coordenadas dos vértices limítrofes que compõem o perímetro de um imóvel rural.

Normalmente, na determinação das coordenadas dos vértices de apoio básico, utiliza-se do sistema de posicionamento GPS, em virtude das estações de referência geodésicas do IBGE estarem localizadas a grandes distâncias da área a ser levantada. Estas estações de referência deverão ser ativas e/ou passivas, homologadas pelo IBGE e pertencentes ao Sistema Geodésico Brasileiro. Quando estas estações estiverem situadas a uma distância superior a $20 \mathrm{~km}$, a Norma Técnica recomenda o uso do transporte direto utilizando-se de receptores de dupla freqüência (L1 e L2) ou que faça o transporte a partir do processo de po- 
ligonal com linhas de base não superiores a $20 \mathrm{~km}$ utilizando-se de receptores de simples freqüência (L1) (INSTITUTO NACIONAL DE COLONIZAÇÃO E REFORMA AGRÁRIA, 2003).

\subsubsection{Transporte utilizando receptores de dupla freqüência}

Para realizar o transporte direto com o intuito de se determinar as coordenadas dos vértices de apoio básico necessita-se de receptores GPS de dupla freqüência e de estações ativas de referência, homologadas pelo IBGE, como determina a Norma Técnica.

Desta forma, na Área 1, onde estavam situados os vértices de apoio A0001 e A0002 e na Área 03, onde se localizavam os vértices A0003 e A0004, utilizou-se o receptor GPS Javad JPS-Legacy para se realizar a coleta dos dados. Na Área 2, onde estavam situados os vértices A0005 e A0006, utilizou-se o receptor GPS Ashtech Z XII. Cada vértice de apoio básico foi rastreado por um período de quatro horas, com uma taxa de coleta de 15 segundos, PDOP inferior a 6 e máscara de elevação de $15^{\circ}$, sendo estas configurações definidas conforme especificações da Norma Técnica do INCRA.

Os dados das estações ativas são partes fundamentais para realização do transporte direto. Assim, foram utilizadas para o processamento dos dados, as estações PPTE, VICO, PARA e CUIB, todas pertencentes à Rede Brasileira de Monitoramento Contínuo - RBMC, localizadas em Presidente Prudente, Viçosa, Curitiba e Cuiabá, respectivamente, com distâncias variando, em relação aos vértices de apoio básico, entre $34 \mathrm{~km}$ a $930 \mathrm{~km}$. Esta quantidade de estações ativas permite aumentar a confiabilidade no valor das coordenadas dos vértices de apoio básico.

Para o processamento dos dados GPS utilizou-se o programa GPSurvey 2.35a da TRIMBLE, em cujo módulo WAVE foram calculados os elementos das linhas de base, sendo adotado para o teste ratio um valor maior ou igual a 3,0 e as variâncias menores que 10 .

Após o processamento, pôde-se verificar que todas as linhas de base foram consideradas aceitas, visto que o teste ratio foi maior que $3 \mathrm{e}$ as variâncias não foram superiores a 5. As componentes $\Delta \mathrm{X}, \Delta \mathrm{Y} \mathrm{e}$ $\Delta \mathrm{Z}$, resultantes dos processamentos das linhas de base, foram ajustadas utilizando-se do programa TRIMNET Plus, de modo a obter uma solução única para a posição dos pontos, bem como estimar a precisão da solução adotada.

\subsubsection{Transporte utilizando receptores de simples freqüência}

Para os profissionais de levantamento que não dispõem de receptores GPS de dupla freqüência, uma outra forma de determinar as coordenadas dos vértices de apoio básico é utilizar-se do levantamento 
através de transporte tipo poligonal, com linhas de base que não ultrapassem a distância de $20 \mathrm{~km}$, conforme especificado na Norma Técnica do INCRA.

Na determinação das coordenadas dos vértices de apoio básico utilizou-se de um par de receptores GPS TRIMBLE 4600 LS, de simples freqüência. Este transporte tipo poligonal, com lances não superiores a 20 km, iniciou-se na estação PPTE, pertencente à Rede Brasileira de Monitoramento Contínuo - RBMC, localizada em Presidente Prudente, SP, passando pelos vértices de apoio básico e fechando na estação VENC, de coordenadas conhecidas da Rede GPS passiva pertencente ao ITESP, na cidade de Presidente Venceslau, SP.

Para cada linha de base a coleta de dados GPS variou de um intervalo de tempo entre 30 a 40 minutos, possibilitando dessa forma que a ambigüidade fosse solucionada. Estes receptores foram configurados com uma máscara de elevação de $15^{\circ}$ e com intervalo de coleta de 15 segundos, conforme prescrições na Norma Técnica.

Durante o processamento das linhas de base, os critérios utilizados para análise foram os empregados no transporte direto. Os testes ratio e de variância foram aceitos ao final do processamento e desta forma, ao ajustamento da poligonal GPS pode ser realizada.

\subsection{Determinação das coordenadas dos vértices limítrofes}

$\mathrm{Na}$ determinação das coordenadas dos vértices limítrofes, a partir das coordenadas dos vértices de apoio básico, podem ser utilizados, segundo a Norma Técnica, o posicionamento através de GPS ou através de técnicas convencionais; sendo através do sistema GPS, os métodos de posicionamento relativo estático ou cinemático.

Segundo Monico (2000), as coordenadas obtidas com a utilização do sistema GPS através do método de posicionamento relativo estático, com tempo de coleta de no mínimo 20 minutos, apresenta maior confiabilidade em seu resultado, visto que, em razão da duração da coleta de dados ser relativamente longa, as ambigüidades são facilmente solucionadas no processo de ajustamento. Isso se deve à alteração da geometria dos satélites durante a sessão, reduzindo a correlação entre as componentes da base e as ambigüidades envolvidas.

Apesar do tempo de ocupação no ponto estação ser relativamente longo, o método fornece uma precisão que atende ao prescrito na Norma, sendo desta forma adotado o método de posicionamento relativo estático para a determinação das coordenadas dos vértices limítrofes de cada área. 
Foram utilizados os processos de poligonação e dupla irradiação, dentro do contexto de posicionamento relativo estático, para a determinação das coordenadas dos vértices que compõem o perímetro de cada área.

Esses levantamentos deverão ter como coordenadas de referência (base) os vértices de apoio básico ou de estações ativas e/ou passivas homologadas pelo IBGE, desde que estas estejam a uma distância inferior a $20 \mathrm{~km}$, como estabelecido na Norma Técnica.

Tanto o método de poligonação como o de dupla irradiação foi realizado nas três áreas. Para isso utilizou-se de um par de receptores GPS TRIMBLE $4600 \mathrm{LS}$, que foram configurados de acordo com os valores especificados na Norma Técnica, tempo de coleta em cada vértice limítrofe de 30 minutos, taxa de coleta de 15 segundos, PDOP inferior a 6 e máscara de elevação de $15^{\circ}$.

\subsubsection{Processo por poligonação}

No método de poligonação utilizando GPS, cada alinhamento que delimita uma área é ocupado sucessivamente, partindo de um vértice de apoio básico e fechando em outro pertencente à mesma área. Ocupou-se durante um período mínimo de 30 minutos cada lance da poligonal. Neste caso, os levantamentos apresentaram observações redundantes, sendo possível realizar o ajustamento.

As análises do processamento das linhas de base do levantamento dos vértices limítrofes, utilizando o método de poligonação, seguiram o mesmo critério das avaliações feitas para a determinação das coordenadas dos vértices de apoio básico. Os processamentos dos dados foram aceitos, pois apresentaram teste ratio superior a 3 e variâncias inferiores a 10, permitindo a realização do ajustamento das linhas de base, e obtendo uma solução única para a posição de cada ponto e a estimativa de sua precisão.

\subsubsection{Processo por dupla irradiação}

A dupla irradiação consiste num processo no qual cada vértice limítrofe da propriedade é irradiado a partir de dois vértices de apoio básico distintos, ou seja, cada vértice do perímetro é ocupado duas vezes. Realizou-se este método no intuito de se obter maior confiabilidade nos valores das coordenadas dos vértices, uma vez que no processo de simples irradiação este controle não é obtido. Além disso, este procedimento permite redundância para realizar o ajustamento das linhas de base.

Portanto, na coleta de dados, ocupou-se um vértice de apoio básico de uma determinada área com um receptor GPS e percorreram-se os vértices limítrofes desta área com o outro equipamento GPS, per- 
manecendo, no mínimo, durante 30 minutos em cada vértice; em seguida ocupou-se o outro vértice de apoio básico e foram percorridos novamente os mesmos vértices do perímetro.

As análises dos processamentos das linhas de base e o ajustamento foram realizados da mesma forma que na poligonação, sendo ambas aceitas.

\section{RESULTADOS E DISCUSSÃO}

Os métodos de levantamentos utilizados no desenvolvimento desse trabalho tiveram como objetivo o georreferenciamento de imóveis rurais, e desta forma, verificar se os mesmos atendem às prescrições estabelecidas na Norma Técnica do INCRA.

Para isso, as discrepâncias entre as coordenadas dos vértices limítrofes para cada método utilizado foram analisadas, bem como a acurácia na determinação das coordenadas dos vértices comuns aos imóveis contíguos para cada método.

3.1 Coordenadas dos vértices de apoio básico obtidos a partir de receptores de dupla freqüência

As coordenadas geodésicas no sistema WGS-84, resultantes do processamento dos dados e do ajustamento das linhas de base, foram transformadas para o sistema UTM - SAD-69. Na Tabela 1 são apresentadas as coordenadas e suas precisões.

Tabela 1 - Coordenadas e precisões dos vértices de apoio obtidas com receptores de dupla freqüência.

\begin{tabular}{llllll}
\hline $\begin{array}{l}\text { Apoio } \\
\text { básico }\end{array}$ & $\mathbf{E}(\mathbf{m})$ & $\boldsymbol{\sigma}_{\mathbf{E}}(\mathbf{m})$ & $\mathbf{N}(\mathbf{m})$ & $\boldsymbol{\sigma}_{\mathbf{N}}(\mathbf{m})$ & $\begin{array}{l}\text { Precisão } \\
\text { métrica }(\mathbf{m})\end{array}$ \\
\hline $\mathrm{A} 0001$ & 428361,680 & 0,004 & 7535475,115 & 0,005 & 0,006 \\
$\mathrm{~A} 0002$ & 428829,642 & 0,004 & 7535436,800 & 0,009 & 0,010 \\
$\mathrm{~A} 0003$ & 428525,374 & 0,011 & 7532915,606 & 0,014 & 0,018 \\
$\mathrm{~A} 0004$ & 428357,338 & 0,016 & 7532650,057 & 0,018 & 0,024 \\
$\mathrm{~A} 0005$ & 428682,724 & 0,009 & 7534258,234 & 0,008 & 0,012 \\
$\mathrm{~A} 0006$ & 428917,558 & 0,018 & 7533681,256 & 0,020 & 0,027 \\
\hline
\end{tabular}


A Norma Técnica do INCRA estabelece que o valor da precisão para a determinação das coordenadas de apoio básico é de +/- 0,100 m. Desta forma, pode-se verificar na Tabela 1 que o método adotado atendeu à prescrição estabelecida pela Norma Técnica, pois o pior valor da precisão foi no vértice A0006, de $0,027 \mathrm{~m}$.

3.2 Coordenadas dos vértices de apoio básico obtidas a partir de receptores de simples freqüência

As coordenadas e precisões dos vértices de apoio básico, no sistema UTM - SAD-69, determinadas com receptores de simples freqüência, são apresentadas na Tabela 2.

Tabela 2 - Coordenadas e precisões dos vértices de apoio obtidas com receptores de simples freqüência.

\begin{tabular}{|c|c|c|c|c|c|c|}
\hline Área & $\begin{array}{l}\text { Apoio } \\
\text { Básico }\end{array}$ & $\mathbf{E}(\mathbf{m})$ & $\sigma_{\mathrm{E}}(\mathrm{m})$ & $\mathbf{N}(\mathbf{m})$ & $\sigma_{N}(\mathbf{m})$ & $\begin{array}{l}\text { Precisão Planimé- } \\
\text { trica }(m)\end{array}$ \\
\hline \multirow{2}{*}{1} & A0001 & 428361,664 & 0,063 & 7535475,131 & 0,060 & 0,087 \\
\hline & A0002 & 428829,615 & 0,058 & 7535436,802 & 0,056 & 0,080 \\
\hline \multirow{2}{*}{2} & A0005 & 428682,732 & 0,062 & 7534258,385 & 0,064 & 0,089 \\
\hline & A0006 & 428917,586 & 0,066 & 7533681,276 & 0,017 & 0,068 \\
\hline \multirow{2}{*}{3} & A0003 & 428525,395 & 0,067 & 7532915,622 & 0,052 & 0,085 \\
\hline & A0004 & 428357,346 & 0,063 & 7532650,069 & 0,047 & 0,079 \\
\hline
\end{tabular}

Na Tabela 2 verifica-se que a precisão planimétrica no transporte de coordenadas utilizando receptores de simples freqüência alcançou o valor de $0,089 \mathrm{~m}$, ou seja, próximo ao valor limite estabelecido pela Norma Técnica que é de $0,100 \mathrm{~m}$. Possivelmente este valor está relacionado com o número de lances da poligonal GPS, que no caso foram seis. Deste modo, à medida que se acrescenta um lance no transporte usando linhas de base, a precisão da poligonal pode se degradar devido à propagação dos erros. 
3.3 Discrepâncias das coordenadas dos vértices de apoio básico obtidas a partir de receptores de dupla e simples freqüência

A utilização de receptores de simples e dupla freqüência permite realizar uma comparação entre as coordenadas obtidas após o ajustamento para cada um dos métodos de levantamento, bem como uma análise de consistência dos resultados.

A Tabela 3 apresenta as discrepâncias entre as coordenadas dos vértices de apoio básico obtidos dos levantamentos com dupla freqüência e simples freqüência.

Tabela 3 - Discrepâncias entre as coordenadas de apoio básico obtidas com GPS de dupla e simples freqüência.

\begin{tabular}{lccl}
\hline $\begin{array}{l}\text { Apoio } \\
\text { Básico }\end{array}$ & $\boldsymbol{\Delta E}(\mathbf{m})$ & $\boldsymbol{\Delta} \mathbf{N}(\mathbf{m})$ & $\begin{array}{l}\text { Resultante } \\
\text { Planimétrica }(\mathbf{m})\end{array}$ \\
\hline A0001 & 0,016 & 0,016 & 0,023 \\
A0002 & 0,027 & $-0,002$ & 0,027 \\
A0003 & $-0,021$ & $-0,016$ & 0,026 \\
A0004 & $-0,008$ & $-0,012$ & 0,014 \\
A0005 & $-0,008$ & $-0,020$ & 0,021 \\
A0006 & $-0,015$ & $-0,033$ & 0,036 \\
\hline Média & $-0,002$ & $-0,011$ & 0,025 \\
Desvio & 0,019 & 0,017 & 0,007 \\
\hline
\end{tabular}

Analisando a Tabela 3 observa-se que a resultante planimétrica média foi de $0,025 \mathrm{~m}$, valor este inferior ao estabelecido na Norma Técnica, de 0,100 m. Isso demonstra que as coordenadas resultantes do levantamento, a partir dos dois processos, apresentam alta confiabilidade.

Para as análises posteriores consideraram-se as coordenadas obtidas através do transporte direto, utilizando receptores GPS de dupla freqüência (L1 e L2), como as verdadeiras, pois, conforme Tabela 1, apresentaram valores de precisão planimétrica menores do que as determinadas por GPS utilizando simples freqüência. 
3.4 Coordenadas dos vértices limítrofes obtidas a partir do posicionamento relativo estático através do processo de poligonação

As coordenadas e suas respectivas precisões dos vértices limítrofes das três áreas no sistema UTM-SAD-69, obtidas através do método de posicionamento relativo estático GPS, usando o processo de poligonação, podem ser observadas na Tabela 4.

Tabela 4 - Coordenadas no sistema UTM - SAD-69 obtidas a partir do processo de poligonação.

\begin{tabular}{|c|c|c|c|c|c|c|}
\hline Área & Ponto & $\mathbf{E}(\mathbf{m})$ & $\sigma_{E}(m)$ & $\mathbf{N}(\mathbf{m})$ & $\sigma_{N}(m)$ & $\begin{array}{l}\text { Precisão Pla- } \\
\text { nimétrica (m) }\end{array}$ \\
\hline \multirow{5}{*}{1} & M0001 & 428016,880 & 0,002 & 7535960,290 & 0,002 & 0,003 \\
\hline & M0002 & 429408,291 & 0,011 & 7535955,434 & 0,007 & 0,013 \\
\hline & M0003 & 429271,757 & 0,009 & 7534956,710 & 0,008 & 0,012 \\
\hline & M0004 & 428490,887 & 0,009 & 7534477,616 & 0,009 & 0,013 \\
\hline & M0005 & 427978,485 & 0,003 & 7534986,464 & 0,003 & 0,004 \\
\hline \multirow{6}{*}{2} & M0003 & 429271,724 & 0,004 & 7534956,684 & 0,003 & 0,005 \\
\hline & M0004 & 428490,851 & 0,005 & 7534477,588 & 0,005 & 0,007 \\
\hline & M0005 & 427978,437 & 0,006 & 7534986,459 & 0,005 & 0,008 \\
\hline & M0006 & 427716,698 & 0,006 & 7533644,717 & 0,006 & 0,008 \\
\hline & M0007 & 428783,922 & 0,006 & 7533374,500 & 0,006 & 0,008 \\
\hline & M0008 & 429879,957 & 0,005 & 7532678,992 & 0,005 & 0,007 \\
\hline \multirow{5}{*}{3} & M0006 & 427716,673 & 0,002 & 7533644,766 & 0,002 & 0,003 \\
\hline & M0007 & 428783,898 & 0,003 & 7533374,548 & 0,003 & 0,004 \\
\hline & M0008 & 429879,925 & 0,004 & 7532679,036 & 0,003 & 0,005 \\
\hline & M0009 & 428799,022 & 0,004 & 7531793,636 & 0,004 & 0,006 \\
\hline & M0010 & 427650,425 & 0,003 & 7532636,415 & 0,003 & 0,004 \\
\hline
\end{tabular}

Analisando as precisões planimétricas da Tabela 4, verifica-se que os vértices M0002 e M0004, da Área 1, apresentaram o pior resultado, de $0,013 \mathrm{~m}$. Porém, este valor é muito menor que o estipulado na Norma Técnica, de $0,500 \mathrm{~m}$. 
3.5 Coordenadas dos vértices limítrofes obtidas a partir do posicionamento relativo estático através do processo de dupla irradiação

Na Tabela 5 são apresentadas as coordenadas e precisões obtidas através do método de posicionamento relativo estático GPS, a partir do processo de dupla irradiação.

Tabela 5 - Coordenadas nos sistema UTM - SAD-69 obtidas a partir do processo de dupla irradiação.

\begin{tabular}{|c|c|c|c|c|c|c|}
\hline Área & Vértices & $\mathbf{E}(\mathbf{m})$ & $\sigma_{\mathrm{E}}(\mathbf{m})$ & $\mathbf{N}(\mathbf{m})$ & $\sigma_{N}(\mathbf{m})$ & $\begin{array}{l}\text { Precisão Planimé- } \\
\text { trica }(m)\end{array}$ \\
\hline \multirow{5}{*}{1} & M0001 & 428016,879 & 0,009 & 7535960,302 & 0,010 & 0,013 \\
\hline & M0002 & 429408,302 & 0,024 & 7535955,407 & 0,020 & 0,031 \\
\hline & M0003 & 429271,771 & 0,007 & 7534956,682 & 0,007 & 0,010 \\
\hline & M0004 & 428490,902 & 0,008 & 7534477,588 & 0,009 & 0,012 \\
\hline & M0005 & 427978,485 & 0,007 & 7534986,464 & 0,006 & 0,009 \\
\hline \multirow{6}{*}{2} & M0003 & 429271,718 & 0,004 & 7534956,681 & 0,004 & 0,006 \\
\hline & M0004 & 428490,850 & 0,003 & 7534477,588 & 0,003 & 0,004 \\
\hline & M0005 & 427978,437 & 0,003 & 7534986,454 & 0,003 & 0,004 \\
\hline & M0006 & 427716,701 & 0,004 & 7533644,712 & 0,003 & 0,005 \\
\hline & M0007 & 428783,919 & 0,003 & 7533374,491 & 0,002 & 0,004 \\
\hline & M0008 & 429879,956 & 0,006 & 7532678,992 & 0,007 & 0,009 \\
\hline \multirow{5}{*}{3} & M0006 & 427716,701 & 0,020 & 7533644,724 & 0,020 & 0,038 \\
\hline & M0007 & 428783,956 & 0,018 & 7533374,596 & 0,015 & 0,023 \\
\hline & M0008 & 429879,942 & 0,022 & 7532679,010 & 0,027 & 0,050 \\
\hline & M0009 & 428799,044 & 0,032 & 7531793,518 & 0,022 & 0,039 \\
\hline & M0010 & 427650,280 & 0,012 & 7532636,430 & 0,023 & 0,026 \\
\hline
\end{tabular}

$\mathrm{Na}$ Tabela 5 verifica-se que a pior precisão planimétrica encontrada foi de $0,050 \mathrm{~m}$, no vértice M0008 da Área 3. Porém, este valor é dez vezes melhor que o limite estabelecido pela Norma Técnica, que é de $0,500 \mathrm{~m}$. 
3.6 Discrepâncias entre as coordenadas dos vértices limítrofes obtidas a partir do posicionamento relativo estático através do processo de poligonação e dupla irradiação

Na Tabela 6 são analisadas as resultantes planimétricas, oriundas da diferença entre as coordenadas dos levantamentos por dupla irradiação e poligonação, dos vértices limítrofes que foram obtidas do levantamento GPS, com receptores de simples freqüência.

Tabela 6 - Discrepâncias entre as coordenadas obtidas a partir dos processos de dupla irradiação e poligonação.

\begin{tabular}{lllll}
\hline Área & Vértice & $\boldsymbol{\Delta} \mathbf{E}(\mathbf{m})$ & $\boldsymbol{\Delta N}(\mathbf{m})$ & $\begin{array}{l}\text { Resultante } \\
\text { Planimétrica }(\mathbf{m})\end{array}$ \\
\hline \multirow{4}{*}{1} & M0001 & 0,001 & $-0,012$ & 0,012 \\
& M0002 & $-0,011$ & 0,027 & 0,029 \\
& M0003 & $-0,014$ & 0,028 & 0,031 \\
& M0004 & $-0,015$ & 0,028 & 0,032 \\
& M0005 & 0,000 & 0,000 & 0,000 \\
\hline \multirow{4}{*}{2} & M0003 & $-0,006$ & 0,003 & 0,007 \\
& M0004 & 0,001 & 0,000 & 0,001 \\
& M0005 & 0,000 & 0,005 & 0,005 \\
& M0006 & $-0,003$ & 0,005 & 0,005 \\
& M0007 & 0,003 & 0,009 & 0,009 \\
& M0008 & 0,001 & 0,000 & 0,001 \\
\hline \multirow{4}{*}{3} & M0006 & $-0,028$ & 0,042 & 0,050 \\
& M0007 & $-0,058$ & $-0,048$ & 0,075 \\
& M0008 & $-0,017$ & 0,026 & 0,031 \\
& M0009 & $-0,022$ & 0,118 & 0,120 \\
& M0010 & 0,145 & $-0,015$ & 0,146 \\
\hline Média & Desvio Padrão & $-0,003$ & 0,014 & 0,035 \\
\hline
\end{tabular}


Verifica-se na Tabela 6 que a resultante planimétrica que atingiu a maior discrepância foi a de 0,146 m, no vértice M0010, da Área 3. Entretanto, atendeu ao estabelecido na Norma Técnica, que é de no máximo $0,500 \mathrm{~m}$.

\subsection{Acurácia entre as coordenadas dos vértices limítrofes comuns no processo de dupla ir-} radiação

Uma outra especificação da Norma Técnica é com relação à avaliação do georreferenciamento. Esta avaliação é realizada a partir da análise da acurácia entre as coordenadas dos vértices limítrofes comuns das propriedades. Desta forma, consideraram-se as coordenadas da Área 2 como certificadas pelo INCRA e são apresentadas na Tabela 7 as discrepâncias entre os vértices comuns das Áreas 1 e 2 e das Áreas 2 e 3, utilizando-se o processo de dupla irradiação.

Tabela 7 - Acurácia entre as coordenadas dos vértices comuns utilizando-se o processo de dupla irradiação.

\begin{tabular}{|c|c|c|c|c|c|}
\hline Processo & Áreas & Vértices & $\Delta \mathrm{E}(\mathrm{m})$ & $\Delta \mathbf{N}(\mathbf{m})$ & $\begin{array}{l}\text { Resultante } \\
\text { Planimétrica (m) }\end{array}$ \\
\hline \multirow{6}{*}{ 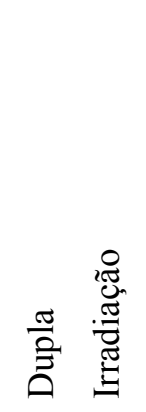 } & 01 & M0003 & $-0,053$ & $-0,001$ & 0,054 \\
\hline & $\mathrm{e}$ & M0004 & $-0,052$ & 0,000 & 0,052 \\
\hline & 02 & M0005 & $-0,048$ & $-0,010$ & 0,049 \\
\hline & 02 & M0006 & 0,000 & $-0,012$ & 0,012 \\
\hline & $\mathrm{e}$ & M0007 & $-0,037$ & $-0,105$ & 0,112 \\
\hline & 03 & M0008 & 0,014 & $-0,018$ & 0,023 \\
\hline \multicolumn{2}{|l|}{ Média } & & $-0,029$ & $-0,024$ & 0,050 \\
\hline \multicolumn{2}{|c|}{ Desvio Padrão } & & 0,029 & 0,040 & 0,035 \\
\hline
\end{tabular}

Analisando a Tabela 7 verifica-se que o vértice M0007 teve uma resultante de $0,112 \mathrm{~m}$, o pior resultado, porém este valor atende à prescrição estabelecida pela Norma Técnica do INCRA que é de $0,500 \mathrm{~m}$. 
3.8 Acurácia entre as coordenadas dos vértices limítrofes comuns no processo de poligonação

Na Tabela 8 observam-se as discrepâncias entre as coordenadas dos vértices comuns das Áreas 1 e 2 e das Áreas 2 e 3 a partir da metodologia de poligonação.

Verifica-se na Tabela 8 que a pior resultante planimétrica, ou seja, a maior diferença de coordenadas entre dois vértices comuns, ocorreu no vértice M0006, de 0,055 m. Porém, inferior ao valor estabelecido na Norma Técnica, que é de $0,500 \mathrm{~m}$.

Tabela 8 - Acurácia entre as coordenadas dos vértices comuns utilizando o processo de poligonação.

\begin{tabular}{|c|c|c|c|c|c|}
\hline Técnica & Áreas & Vértice & $\Delta \mathbf{E}(\mathbf{m})$ & $\Delta \mathbf{N}(\mathbf{m})$ & $\begin{array}{l}\text { Resultante } \\
\text { Planimétrica (m) }\end{array}$ \\
\hline \multirow{6}{*}{ 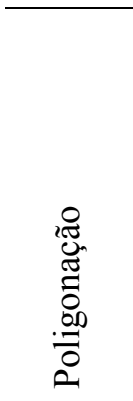 } & 01 & M0003 & $-0,033$ & $-0,026$ & 0,042 \\
\hline & $\mathrm{e}$ & M0004 & $-0,036$ & $-0,028$ & 0,046 \\
\hline & 02 & M0005 & $-0,048$ & $-0,005$ & 0,048 \\
\hline & $\overline{02}$ & M0006 & 0,025 & $-0,049$ & 0,055 \\
\hline & $\mathrm{e}$ & M0007 & 0,024 & $-0,048$ & 0,054 \\
\hline & 03 & M0008 & 0,032 & $-0,044$ & 0,054 \\
\hline \multicolumn{2}{|l|}{ Média } & & $-0,006$ & 0,033 & 0,050 \\
\hline \multicolumn{2}{|c|}{ Desvio Padrão } & & 0,037 & 0,017 & 0,005 \\
\hline
\end{tabular}

\section{CONCLUSÕES}

Os processos usados no georreferenciamento de imóveis rurais, empregados neste trabalho, tiveram como objetivos, identificar procedimentos e metodologias de levantamentos utilizando-se do método de posicionamento relativo estático. 
Para alcançar tais objetivos, análises dos processamentos nos levantamentos por GPS, valores das precisões das coordenadas dos vértices limítrofes, as discrepâncias entre as coordenadas dos vértices e a acurácia entre as coordenadas de vértices comuns foram realizadas, e pôde-se concluir que os resultados obtidos foram satisfatórios, alcançando em todas as metodologias estudadas as precisões e discrepâncias exigidas na Norma Técnica do INCRA, na qual se baseia este trabalho.

$\mathrm{Na}$ determinação das coordenadas dos vértices limítrofes foi possível observar que o posicionamento relativo estático a partir do uso de receptor GPS de simples freqüência, com tempo de coleta em cada vértice de 30 minutos, é um procedimento rigoroso, onde as ambigüidades são facilmente solucionadas no processo de ajustamento, e apresentam à sua final maior confiabilidade nos valores das coordenadas.

No posicionamento relativo estático, duas metodologias foram apresentadas: poligonação e dupla irradiação. Outras possibilidades vão depender dos equipamentos disponíveis pelos usuários, no entanto é importante salientar que os métodos apresentados permitem um controle de qualidade do levantamento, pois apresentam redundância na coleta dos dados em campo, e dessa forma é possível realizar o ajustamento.

Pelos resultados apresentados qualquer das metodologias, poligonação ou dupla irradiação, poderiam ser utilizadas como certificadas ou verdadeiras, pois ambas forneceram resultados que atenderam plenamente as especificações da Norma Técnica.

Porém, estes resultados só podem ser analisados em virtude da redundância de observações, onde cada vértice limítrofe do imóvel é ocupado pelo menos duas vezes. Isso permitiu avaliar a precisão das coordenadas de cada um dos vértices e não somente a partir da qualidade de cada programa, que pode levar a conclusões precipitadas, visto que os valores resultantes dos processamentos dos dados GPS são sempre muito otimistas.

\section{REFERÊNCIAS}

BRASIL. Lei n. 10.267, de 28 de agosto de 2001. Altera dispositivos das Leis n. 4.947, de 6 de abril de 1966, 5.868, de 12 de dezembro de 1972, 6.015, de 31 de dezembro de 1973, 6.739, de 5 de dezembro de 1979, 9.393, de 19 de dezembro de 1996, e dá outras providências. Diário Oficial da União: Poder Legis- 
lativo, Brasília, DF, v. 1, p.1, 29 dez. 2001. Disponível em:

$<$ http://www6.senado.gov.br/legislacao/ListaTextoIntegral.action?id=220742>. Acesso em: 05 jun. 2004.

BRASIL. Decreto n. 4.449, de 22 de outubro de 2002. Dispõe sobre a regulamentação da Lei n ${ }^{0} 10.267$.

Diário Oficial da União: Poder Executivo, Brasília, DF, v. 1, p. 3, 31 out. 2002a. Disponível em:

$<$ http://www6.senado.gov.br/legislacao/ListaTextoIntegral.action?id=222815>. Acesso em: 05 jun. 2004.

BRASIL. Instituto Nacional de Colonização e Reforma Agrária. Portaria n. 954, de 13 de novembro de 2002. Diário Oficial, Brasília, DF, n. 222, Seção 1, 18 nov. 2002b. Disponível em:

$<$ http://www.incra.gov.br/portal/index.php?option $=$ com_docman\&task=doc_download\&gid=46\&Itemid= 133>. Acesso em 06 set. 2005.

INSTITUTO NACIONAL DE COLONIZAÇÃO E REFORMA AGRÁRIA. Norma técnica para georreferenciamento de imóveis rurais. Brasília, DF, 2003. Disponível em:

$<$ http://200.252.80.40/Credencia/download/Norma_Tecnica.pdf $>$. Acesso em: 05 jun. 2006.

MONICO, J. F. G. Posicionamento pelo NAVSTAR - GPS: descrição, fundamentos e aplicações. São Paulo: UNESP, 2000. 287 p.

MONICO, J. F. G; SILVA, E. F. Controle de qualidade em levantamentos no contexto da Lei n. 10.267/01. In: COLÓQUIO BRASILEIRO DE CARTOGRAFIA, 3., 2003, Curitiba. Anais ... Curitiba: UFPR, 2003. p. 69-84

TEUNISSEN, P. J. G. Testing theory: an introduction. Neatherlands: Delft University Press, 2000. 147 p. 